\title{
Candidate gene analysis of ocular toxoplasmosis in Brazil: evidence for a role for toll-like receptor 9 (TLR9)
}

\author{
Alba L Peixoto-Rangel ${ }^{1,2,3}$, E Nancy Miller², Léa Castellucci ${ }^{2,4}$, Sarra E Jamieson ${ }^{2,5}$, \\ Ricardo Guerra Peixe ${ }^{1}$, Liliani de Souza Elias ${ }^{1}$, Rodrigo Correa-Oliveira ${ }^{3}$, \\ Lílian MG Bahia-Oliveira1, Jenefer M Blackwell ${ }^{2,5}{ }^{+}$
}

\begin{abstract}
${ }^{1}$ Universidade Estadual do Norte Fluminense Darcy Ribeiro, Campos dos Goytacazes, RJ, Brasil ${ }^{2}$ Cambridge Institute for Medical Research and Department of Medicine, University of Cambridge School of Clinical Medicine, Cambridge, UK ${ }^{3}$ Instituto de Pesquisas René Rachou-Fiocruz, Belo Horizonte, MG, Brasil ${ }^{4}$ Universidade Federal da Bahia, Salvador, BA, Brasil ${ }^{5}$ Telethon Institute for Child Health Research, Centre for Child Health Research, The University of Western Australia, Subiaco, Australia
\end{abstract}

Toxoplasma gondii infection is an important mediator of ocular disease in Brazil more frequently than reported from elsewhere. Infection and pathology are characterized by a strong proinflammatory response which in mice is triggered by interaction of the parasite with the toll-like receptor (TLR)/MyD88 pathway. A powerful way to identify the role of TLRs in humans is to determine whether polymorphisms at these loci influence susceptibility to T. gondiimediated pathologies. Here we report on a small family-based study (60 families; 68 affected offspring) undertaken in Brazil which was powered for large effect sizes using single nucleotide polymorphisms with minor alleles frequencies > 0.3. Of markers in TLR2, TLR5 and TLR9 that met these criteria, we found an association Family Based Association Tests $\left[(F B A T) Z\right.$ score $\left.=4.232 ; p=1.5 \times 10^{-5} ; p_{\text {corrected }}=1.2 \times 10^{-4}\right]$ between the C allele (frequency $=0.424$; odds ratio = 7; 95\% confidence interval 1.6-30.8) of rs352140 at TLR9 and toxoplasmic retinochoroiditis in Brazil. This supports the hypothesis that direct interaction between T. gondii and TLR9 may trigger proinflammatory responses that lead to severe pathologies such as the ocular disease that is associated with this infection in Brazil.

Key words: toxoplasmosis - genetic polymorphisms - toll-like receptors - toxoplasmic retinochoroiditis - Brazil

Toxoplasma gondii infection has emerged as an important mediator of both congenital and post-natally acquired ocular disease in Brazil (Melamed 2009). Infection in both mice and humans is characterized by high levels of proinflammatory cytokines, such as interleukin (IL)- 12 , tumour necrosis factor (TNF)- $\alpha$ and interferon- $\gamma$, all of which have been implicated in ocular pathology (Garweg \& Candolfi 2009, Lahmar et al. 2009). There has therefore been great interest in identifying the initial triggers for this proinflammatory host response to the parasite, in particular the role of innate immune pathways triggered by the interaction of the pathogen with the toll-like receptor (TLR)/ myeloid differentiation primary response gene 88 (MyD88) pathway.

The existence of $T$. gondii TLR ligands was initially inferred by the observation that mice lacking MyD88 were highly susceptible to infection (Scanga et al. 2002). The possibility that multiple ligands might be present was indicated by the ability of different fractions of tachyzoite lysates to trigger both MyD88-dependent IL12 and MyD88-dependent chemokine (CCL2/MCP1) re-

Financial support: CAPES (BEX 2371/06-05), CNPq (151950/2008-3, 558876/2008-0), FAPERJ (E-26/112045/2008)

LMGB-O and JMB contributes equally to this work.

+ Corresponding author: jmb37@cam.ac.uk

Received 6 August 2009

Accepted 10 November 2009 sponses (Del Rio et al. 2004). Fractionation of tachyzoite lysate antigen led to identification of a parasite molecule that triggered TLR11, a TLR present in mice but not in humans (Yarovinsky et al. 2005). Biochemical studies using Chinese hamster ovary cells co-transfected with TLRs and nuclear factor $\kappa \mathrm{B}(\mathrm{NFkB})$ reporter plasmids have also shown that $T$. gondii glycosylphosphatidylinositol (GPI) molecules are recognized by TLR4 (Debierre-Grockiego et al. 2003). Core glycans and lipid moieties obtained from parasite GPI are recognized by both TLR2 and TLR4, both of which mediate recognition of T. gondii GPI in mouse macrophages as measured by induction of TNF- $\alpha$ (Debierre-Grockiego et al. 2007). Mice deficient in both TLR2 and TLR4, but not TLR2 alone, show complete abrogation of TNF- $\alpha$ in response to GPI (Debierre-Grockiego et al. 2007). This suggests that TLR2 and TLR4 cooperate during T. gondii infection. Similar conclusions have been made in relation to cooperation between TLR2-TLR9 in mediating protection against Trypanosoma cruzi infection in mice (Bafica et al. 2006), as well as in models of Mycobacterium tuberculosis infection (Bafica et al. 2005). T. gondii heat shock protein 70 has also been implicated in maturation of dendritic cells via TLR4 (Aosai et al. 2006) and an important indirect effect of TLR4 stimulation is seen in induction of inflammation in the small intestine following oral infection of mice due to substantial overgrowth of commensals in the ileum (Heimesaat et al. 2007). Lack of TLR4 prevents T. gondii induced ileitis. TLR9 deficient mice also show reduced $T$. gondii induced ileitis, in this case also associated with a reduced $\mathrm{T}$ helper 1 re- 
sponse to the parasite in the small intestine and lamina propria, suggesting that TLR9 might be directly involved in parasite recognition (Minns et al. 2006). Defined parasite ligands for TLR9 in other apicomlexan parasites include genomic DNA from Babesia (Shoda et al. 2001) and hemozoin from Plasmodium falciparum (Coban et al. 2005). However, studies of the interaction of T. gondii with TLR9 transfectants or TLR9 deficient cells suggest that $T$. gondii does not directly trigger TLR9 activation (Yarovinsky 2008).

A powerful way to query the role of different TLRs in humans is to determine whether polymorphisms at these loci influence susceptibility to T. gondii-mediated pathologies such as ocular disease. Here we report on a small family-based study undertaken in Brazil which begins to address this question. For common allelic variants, we provide evidence for a role for TLR9 in ocular disease associated with toxoplasmic retinochoroiditis in Brazil.

DNA from a total of 160 individuals from 60 families was included in the study (Table I); 30 families containing at least one offspring affected with ocular disease due to acquired toxoplasmosis plus parents and 30 families comprising affected individuals plus unaffected sibs. Families were from an area of the city of Campos dos Goytacazes, located in the northern region of the state of Rio de Janeiro (Bahia-Oliveira et al. 2003). The study protocol complied with the Helsinki Declaration and was approved by the Ethical Committee of Fundação Oswaldo Cruz-Fiocruz, Brazil (347/06) and the National Ethical Committee (CONEP 013/2007). Written informed consent was obtained from patients according to the guidelines of the Ethical Committee of Fiocruz. All individuals classified as affected were T. gondii-
TABLE I

Details of families used in the Family Based Association Tests analysis

\begin{tabular}{lccccc}
\hline & \multirow{2}{*}{ Families } & \multicolumn{2}{c}{ Children } & & \\
\cline { 3 - 4 } Family type & $\mathrm{n}$ & Affected Unaffected & Parents Total \\
\hline Nuclear families & & & & & \\
1 affected offspring & 28 & 28 & 0 & 56 & 84 \\
2 affected offspring & 2 & 4 & 0 & 4 & 8 \\
Sibships & & & & & \\
1 affected offspring & 25 & 25 & 31 & 0 & 56 \\
2 affected offspring & 4 & 8 & 1 & 0 & 9 \\
3 affected offspring & 1 & 3 & 0 & 0 & 3 \\
Total & & & & & 160 \\
\hline
\end{tabular}

seropositive and presented with posterior retinal/retinochoroidal non active uveitis scars lesions as described (Bahia-Oliveira et al. 2009). Transmission disequilibrium test (TDT) power approximations (Knapp 1999) showed that the 60 families had $\geq 75 \%$ power to detect allelic association at an odds ratio of 3 at $p=0.01$ for markers with minor allele frequencies $(\mathrm{MAF}) \geq 0.3$. Genotyping was performed using Taqman or SNaPshot technologies for single nucleotide polymorphisms (SNPs) at TLR2 (rs38004099, rs5743708), TLR4 (rs4986790, rs4986791), TLR5 (rs1053954, rs1341987) and TLR9 (rs5743836, rs352140). All were in Hardy Weinberg equilibrium in genetically unrelated founders of the families and in a

TABLE II

Family Based Association Tests (FBAT) analysis under additive model of inheritance for associations between toll-like receptor (TLR)/single nucleotide polymorphisms (SNPs) and ocular disease caused by infection with toxoplasmosis in Brazil

\begin{tabular}{|c|c|c|c|c|c|c|}
\hline Gene/SNP & Details & MAF & $\begin{array}{l}\text { milies } \\
\mathrm{n}^{a}\end{array}$ & Allele (strand) & Z score ${ }^{c}$ & p value \\
\hline TLR2_rs3804099 & $\begin{array}{c}\text { exon 3; } \\
\text { Asn-199-Asn }\end{array}$ & 0.476 & 33 & $\mathrm{C}(+)$ & +0.684 & 0.49 \\
\hline TLR2_rs5743708 & $\begin{array}{c}\text { exon 3; } \\
\text { Gln-753-Arg }\end{array}$ & 0.011 & $1^{b}$ & $\mathrm{~A}(+)$ & - & - \\
\hline TLR4_rs4986790 & $\begin{array}{c}\text { exon 3; } \\
\text { Gly-299-Asp }\end{array}$ & 0.089 & $6^{b}$ & $\mathrm{~A}(+)$ & - & - \\
\hline TLR4_rs4986791 & $\begin{array}{c}\text { exon 3; } \\
\text { Ile-399-Thr }\end{array}$ & 0.096 & $8^{b}$ & $\mathrm{C}(+)$ & - & - \\
\hline TLR5_rs1053954 & $\begin{array}{c}\text { exon 6; } \\
\text { Lys-841-Lys }\end{array}$ & 0.092 & 14 & C (-) & -1.246 & 0.21 \\
\hline TLR5_rs1341987 & intron 2 & 0.363 & 35 & G (-) & +0.099 & 0.92 \\
\hline TLR9_rs352140 & $\begin{array}{c}\text { exon 2; } \\
\text { Pro-545-Pro }\end{array}$ & 0.424 & 24 & C (-) & +4.323 & $1.5 \times 10^{-5}$ \\
\hline TLR9_rs5743836 & upstream & 0.216 & 21 & A (-) & -0.063 & 0.95 \\
\hline
\end{tabular}

results are shown for the minor allele. $a$ : number of families informative for the FBAT analysis; $b$ : too few families contributing to the analysis; c: positive $\mathrm{Z}$ score indicates association with disease and a negative $\mathrm{Z}$ score indicates the non-associated or protective allele. MAF: minor allele frequency. 
set of unrelated controls from the same region (data not shown). Family-based allelic association tests based on the TDT but generalized to allow analysis under additive and dominant models of inheritance were performed within Family Based Association Tests (FBAT) (Laird et al. 2000, Horvath et al. 2001) under the null hypothesis of "no linkage and no association". Case-pseudocontrol conditional logistic regression analysis was used to determine effect size (odds ratio) and 95\% confidence interval for allelic association (Cordell et al. 2004). In this test a matched set of pseudocontrols is generated based on the alleles not transmitted from parents to the case. A likelihood ratio test comparing the 1 degree of freedom (df) and $2 \mathrm{df}$ tests was used to determine whether there were dominance effects.

Table II presents the results of FBAT analysis. Only SNPs TLR2 (rs3804099), TLR5 (rs1341987) and TLR9 (rs352140) provided sufficient power for this set of families in having $>10$ families contribute to the FBAT analysis and a MAF $>0.3$. Only data for the additive model are presented as this model provided the best fit for the observed association; the likelihood ratio test provided no evidence for dominance effects. The results indicate a strong association $(\mathrm{Z}$ score $=4.232$; $\mathrm{p}=1.5 \times 10^{-5}$ ) between TLR9 rs352140 and ocular disease associated with $T$. gondii infection in this population, that is robust to correction for multiple testing by the total number $(n=8)$ of SNPs genotyped $\left(\mathrm{p}_{\text {corrected }}\right.$ $=0.00012)$. This observation requires replication in $\mathrm{a}$ separate sample. In this Brazilian population disease was associated with allele $\mathrm{C}$ at rs352140 (odds ratio = $7 ; 95 \%$ confidence interval 1.6-30.8) which was at a frequency of 0.424, similar to that observed in European populations as compared to frequencies of $0.625-0.733$ in African American and Subsaharan African populations (NCBI 2009). The SNP rs352140 causes a synonymous amino acid change encoded in exon 2 so is not the disease causing variant itself, which must lie in linkage disequilibrium with this marker. This study is the first to show TLR9 polymorphisms associated with ocular toxoplasmosis. Therefore, further works will be needed to identify the functional variant and to replicate this association in another sample. Definitive identification of the functional variant will aid in determining whether the pathology associated with ocular disease is associated with the fully functional TLR9 molecule and hence with the possibility that interaction with the parasite is causing an over-active proinflammatory response. An alternative outcome might be that a functional TLR9 variant is associated with enhanced parasite control. In this case the loss-of-function variant would lead to a higher parasite load which, in turn, could result in elevated proinflammatory responses through other innate or acquired immune pathways. In this study, our analysis focused on SNPs that had been used in other disease association studies (Lazarus et al. 2003, Torok et al. 2009), rather than a full analysis of haplotype-tagging SNPs across each gene. Hence, we cannot discount the possibility that associations with TLR2, TLR4 and TLR5 will be observed in other studies, especially if they are more highly powered. For the moment, our study provides promising initial genetic support for the hypothesis that direct interaction between T. gondii and TLR9 may be important in triggering proinflammatory responses that lead to severe pathologies, such as the ocular disease that are associated with this infection in Brazil.

\section{ACKNOWLEDGMENTS}

We thank the ophthalmologists Drs. Daíse Malheiros Meira, Elisa Waked, Fernanda Porto, Fernando Oréfice, Gustavo Heringer and Wesley Campos, for examining patients.

\section{REFERENCES}

Aosai F, Rodriguez Pena MS, Mun HS, Fang H, Mitsunaga T, Norose K, Kang HK, Bae YS, Yano A 2006. Toxoplasma gondii-derived heat shock protein 70 stimulates maturation of murine bone marrow-derived dendritic cells via toll-like receptor 4. Cell Stress Chaperones 11: 13-22.

Bafica A, Santiago HC, Goldszmid R, Ropert C, Gazzinelli RT, Sher A 2006. Cutting edge: TLR9 and TLR2 signaling together account for MyD88-dependent control of parasitemia in Trypanosoma cruzi infection. J Immunol 177: 3515-3519.

Bafica A, Scanga CA, Feng CG, Leifer C, Cheever A, Sher A 2005. TLR9 regulates Th1 responses and cooperates with TLR2 in mediating optimal resistance to Mycobacterium tuberculosis. J Exp Med 202: 1715-1724.

Bahia-Oliveira LMG, da Silva JA, Peixoto-Rangel AL, Boechat MS, Oliveira AM, Massara CL, Peixe RG 2009. Host immune response to Toxoplasma gondii and Ascaris lumbricoides in a highly endemic area: evidence of parasite co-immunomodulation properties influencing the outcome of both infections. Mem Inst Oswaldo Cruz 104: 273-280.

Bahia-Oliveira LMG, Jones JL, Azevedo-Silva J, Alves CC, Orefice F, Addiss DG 2003. Highly endemic, waterborne toxoplasmosis in north Rio de Janeiro state, Brazil. Emerg Infect Dis 9: 55-62.

Coban C, Ishii KJ, Kawai T, Hemmi H, Sato S, Uematsu S, Yamamoto M, Takeuchi O, Itagaki S, Kumar N, Horii T, Akira S 2005. Tolllike receptor 9 mediates innate immune activation by the malaria pigment hemozoin. J Exp Med 201: 19-25.

Cordell HJ, Barratt BJ, Clayton DG 2004. Case/pseudocontrol analysis in genetic association studies: a unified framework for detection of genotype and haplotype associations, gene-gene and gene-environment interactions, and parent-of-origin effects. Genet Epidemiol 26: 167-185.

Debierre-Grockiego F, Azzouz N, Schmidt J, Dubremetz JF, Geyer H, Geyer R, Weingart R, Schmidt RR, Schwarz RT 2003. Roles of glycosylphosphatidylinositols of Toxoplasma gondii. Induction of tumor necrosis factor-alpha production in macrophages. $J$ Biol Chem 278: 32987-32993.

Debierre-Grockiego F, Campos MA, Azzouz N, Schmidt J, Bieker U, Resende MG, Mansur DS, Weingart R, Schmidt RR, Golenbock DT, Gazzinelli RT, Schwarz RT 2007. Activation of TLR2 and TLR4 by glycosylphosphatidylinositols derived from Toxoplasma gondii. J Immunol 179: 1129-1137.

Del Rio L, Butcher BA, Bennouna S, Hieny S, Sher A, Denkers EY 2004. Toxoplasma gondii triggers myeloid differentiation factor 88-dependent IL-12 and chemokine ligand 2 (monocyte chemoattractant protein 1) responses using distinct parasite molecules and host receptors. J Immunol 172: 6954-6960.

Garweg JG, Candolfi E 2009. Immunopathology in ocular toxoplasmosis: facts and clues. Mem Inst Oswaldo Cruz 104: 211-220.

Heimesaat MM, Fischer A, Jahn HK, Niebergall J, Freudenberg M, Blaut M, Liesenfeld O, Schumann RR, Gobel UB, Bereswill S 2007. Exac- 
erbation of murine ileitis by toll-like receptor 4 mediated sensing of lipopolysaccharide from commensal Escherichia coli. Gut 56: 941-948.

Horvath S, Xu X, Laird NM 2001. The family based association test method: strategies for studying general genotype--phenotype associations. Eur J Hum Genet 9: 301-306.

Knapp M 1999. A note on power approximations for the transmission/ disequilibrium test. Am J Hum Genet 64: 1177-1185.

Lahmar I, Abou-Bacar A, Abdelrahman T, Guinard M, Babba H, Ben Yahia S, Kairallah M, Speeg-Schatz C, Bourcier T, Sauer A, Villard O, Pfaff AW, Mousli M, Garweg JG, Candolfi E 2009. Cytokine profiles in toxoplasmic and viral uveitis. J Infect Dis 199: 1239-1249.

Laird NM, Horvath S, Xu X 2000. Implementing a unified approach to family-based tests of association. Genet Epidemiol 19 (Suppl. 1): S36-42.

Lazarus R, Klimecki WT, Raby BA, Vercelli D, Palmer LJ, Kwiatkowski DJ, Silverman EK, Martinez F, Weiss ST 2003. Singlenucleotide polymorphisms in the toll-like receptor 9 gene (TLR9): frequencies, pairwise linkage disequilibrium and haplotypes in three US ethnic groups and exploratory case-control disease association studies. Genomics 81: 85-91.

Melamed J 2009. Contributions to the history of ocular toxoplasmosis in Southern Brazil. Mem Inst Oswaldo Cruz 104: 358-363.

Minns LA, Menard LC, Foureau DM, Darche S, Ronet C, Mielcarz DW, Buzoni-Gatel D, Kasper LH 2006. TLR9 is required for the gut-associated lymphoid tissue response following oral infection of Toxoplasma gondii. J Immunol 176: 7589-7597.
NCBI - National Centre for Biotechnology Information 2009. Single nucleotide polymorphisms [cited 2009 September 23] [updated May 25, 2006]. Available from: http://www.ncbi.nlm.nih.gov/ projects/SNP/snp_ref.cgi?rs=352140.

Scanga CA, Aliberti J, Jankovic D, Tilloy F, Bennouna S, Denkers EY, Medzhitov R, Sher A 2002. Cutting edge: MyD88 is required for resistance to Toxoplasma gondii infection and regulates parasite-induced IL-12 production by dendritic cells. J Immunol 168: 5997-6001

Shoda LK, Kegerreis KA, Suarez CE, Roditi I, Corral RS, Bertot GM, Norimine J, Brown WC 2001. DNA from protozoan parasites Babesia bovis, Trypanosoma cruzi, and T. brucei is mitogenic for B lymphocytes and stimulates macrophage expression of interleukin-12, tumor necrosis factor alpha, and nitric oxide. Infect Immun 69: 2162-2171.

Torok HP, Glas J, Endres I, Tonenchi L, Teshome MY, Wetzke M, Klein W, Lohse P, Ochsenkuhn T, Folwaczny M, Goke B, Folwaczny C, Muller-Myhsok B, Brand S 2009. Epistasis between tolllike receptor-9 polymorphisms and variants in NOD2 and IL23R modulates susceptibility to Crohn's disease. Am J Gastroenterol 104: 1723-1733.

Yarovinsky F 2008. Toll-like receptors and their role in host resistance to Toxoplasma gondii. Immunol Lett 119: 17-21.

Yarovinsky F, Zhang D, Andersen JF, Bannenberg GL, Serhan CN, Hayden MS, Hieny S, Sutterwala FS, Flavell RA, Ghosh S, Sher A 2005. TLR11 activation of dendritic cells by a protozoan profilin-like protein. Science 308: 1626-1629. 